\title{
The Multiple Faces of Mass Customization: Product Design, Process Design and Supply Chain Design
}

\author{
Nico J. Vandaele ${ }^{1,2}$ and Catherine J. Decouttere ${ }^{2}$ \\ ${ }^{1}$ Katholieke Universiteit Leuven, Faculty of Business and Economics, \\ Naamsestraat 69, 3000 Leuven \\ ${ }^{2}$ KULAK, E. Sabbelaan 53, 8500 Kortrijk \\ \{Nico.Vandaele, Catherine. Decouttere\} @kuleuven. be
}

\begin{abstract}
Mass Customization is one of the buzz words of the last decade. However, the purpose of efficiently unfolding multiple variants of a product or service has deep grounded consequences for the business processes and the underlying system. Subsequently, the supply chain structures supporting these processes face many challenges. In this paper we expose an integrated view on mass customization from a design perspective, rooted in a user-oriented design paradigm. First, we want to find an answer to whether mass customization is a feasible business model to guarantee sustainability in the Flemish textile industry. Second, how can the long tail business model be designed in an integrated way, relating product, process and supply chain design. The mass customized product/service design framework is based on field data gathered from a technological innovation supporting programme operational in Flanders' textile industry. Based on these data, some preliminary benchmarking observations can be made which relate to product, process and supply chain design.
\end{abstract}

Keywords: Mass customization, business model innovation, supply chain design.

\section{Introduction}

Mass customization and "the Long Tail" business model, as defined and described by [1], give an answer to the trend of personalization intended at the cost and effort of a standard product or service. "Tailor made" was the traditional way of presenting a perfect fit to a very specific customer need. More specifically for the textile industry, what started off as mainly ergonomic fit (for instance in terms of size), evolved to tailored functionality and individual emotional benefits such as self-expression and uniqueness. The design aspect in the broad sense became an asset creating a willingness to pay. However, companies applying the mass customization business model, need to find a new balance between unique product/service performance and the related cost, while keeping the process and supply chain complexity within feasible limits. Essential elements in this exercise are the co-creation experience, product modularity, and enabling technologies, allowing unique products which are producible in small lot sizes or even in a one-by-one mode. 
In the context of the Technological Support Programme for Mass Customization issued by the Flemish Government, we observed and supported the textile and confection industry in Flanders in its transition to mass customization. With an objective of creating sustainable added value and rejuvenating a traditional but struggling Flemish industry in a global context (suffering from delocalisation), the viewpoints from both the customer and the producer are investigated.

\section{Customization for a Sustainable Textile Industry}

Elements of Sustainability. Sustainability for the Flemish textile industry is translated in to objectives in terms of social, ecological and economical dimensions. On the social level, it was brought down to "keeping jobs in Flanders". Knowing that large parts of the production in the textile industry has been delocalized from Flanders, we see new activities arising in personalized design, research in technical textiles with new functionalities, automated production of small batches or unique one-of-a-kind products based on efficient technology and experience etc. A lot of these new activities deliver goods and services with a high level of customization.

On the ecological level, the overall carbon footprint of the industry is considered. Key elements driving sustainability in a mass customized textile industry are lower material use due to less scrap, lower transportation and extension of life time of products.

The economic benefits of MC in the textile industry are the result of the transition from a make to stock to a make to order approach. Supply chain related costs such as inventory cost and scrap should be significantly lower. This will depend on the accepted order lead time by the customer of the personalized goods.

The textile industry is known to be highly sensitive to fashion and trends, and each season, this "fashion risk" can lead to significant scrap costs due to unsellable goods.

Market Environment. Companies who initially started up with mass customization in a highly customized market, for instance functional sportswear, seem to have a competitive advantage compared to companies who want to make the transition to customization in a market were standard or low customized products and services are the main reference. This is the case with for instance the confection industry or the interior textile industry (curtains and carpets).

However, the theoretical opportunities in the mass production confection industry sector is also high as fashion risk and inventory risks can be minimised by converting away from a mass production business model towards a mass customization business model [8].

Company Profile. Reality reveals that the integration of the voice of the customer and the conversion of the sales approach is yet a hard learning curve for traditional companies, as it usually involves a turnaround of both their innovation and processing approach as well as their distribution and supply network. Moreover, the financial benefits of more lean and sustainable operations are not immediately felt as the turnaround to a mass customization network involves the influx of financial resources. 


\section{Business Opportunities from Customization}

The literature on Mass Customization is vast and elaborate and traces back to Davis [3]. We refer to [2], [10] for a comprehensive review. The added value of addressing individual needs, whether functional or not, need to be reflected in a positive cocreation experience, which guides the customer in a pleasant way from the understanding of his individual needs through the design process and placing the order of the perfectly matching product. In this way, the negative effect on the purchasing process of an overwhelming range of possibilities can be overcome [9]. The degree to which the product and service should be customized in order to obtain optimal added value, is a key question with implications for the entire business model design. A MC company needs to adopt new skills allowing it to gain and maintain a profound insight in its customer's individual needs and expectations. A highly performing customer knowledge system becomes a necessity.

Already from the conception and development of the products and services, the customization approach will be applied. The product, service and system architecture will be in line with the configuration steps the customer will be invited to take part in. The role of designers and product developers changes towards more openness to the voice of the customer, they will balance between reflecting the company identity and brand essence in the customized products and services and providing guidance and reassurance during the co-creation process where it is expected by the customer.

Accordingly, the processing and the delivery of the product/service has to be performed in an efficient and cost effective manner. In one way or another, multiple technological possibilities are there. The Flemish textile industry has a leading position in technical textiles (used for special purposes like fire protection, healthcare applications, etc.), in implementing three-dimensional body-scanning techniques, in digital printing techniques and many more.

Our double entry research question is as follows:

1. Is mass customization a feasible business model to guarantee sustainability in the Flemish textile industry?

2. How can the long tail business model for a Flemish textile company be designed in an integrated way: product, process and supply chain?

In order to answer these questions, an integrated approach amongst product design, process design and supply chain design is at stake.

\section{The MC Product, Process and Business Model Design Framework}

Against this framework, we give an overview of the dimensions which positively and negatively influence the success of mass customization in the Flemish textile industry, using a multi-dimensional approach based on industry data from 2011. These data were collected based on structured interviews, company audits and group 
assessments. Important elements from the data collection were grouped into product, process and business model categories. Subsequently we measured some core KPI's from the companies. At this point we only give an overview of some important key value dimensions.

\subsection{Product/Service Design}

Perceived Usefulness (PU) is here measured as a product attribute with a considerable user involvement and is in this context defined as "the value of customization, i.e. the increment of utility a customer gains from a product that fits better to her needs than the best standard product attainable as perceived by the customer [6]. Examples can be found in sportswear where individual physical characteristics may largely dictate the willingness to deviate from an industrial standard.

Perceived Ease Of Use (PEOU) is the degree to which the co-creation step is pleasant or free of effort for the user. It refers to customer friendly toolkits and configurator applications where the user is led comfortably through his decision process and where positive emotions are elicited during the customizing process.

I Designed It Myself Effect (IDME). Here the feeling of being responsible for the outcome and authoring the design is key. It resembles the 'good' feeling stemming from the actions and the opinions of the customer which turn the product into an element of self-esteem. It is a value-generating effect that arises merely from the fact that the customer is the originator of the product [5].

\subsection{Process Design}

From the process side the degree of Mass Customization (MC) is measured as the degree to which products can be produced, i.e. the ability, to achieve customization, ranging from a solely standard product to a fully customized product.

Process Technology Adaptation (PTA) is the degree to which the company has adapted or employs the adequate process technology to be able to deliver mass customization. Industry known benchmark technologies are used to produce an overall assessment.

\subsection{Business Model Design}

The Point-Of-Sale Effectiveness (POSE) is the degree to which the point of sale is successful in reaching the customer and explaining the benefits of the personalized product offer in an easy way.

Also the organization of the supply chain plays a role and is measured by Supply Chain Network Responsiveness (SCNR). This is measured by the degree to which a company is able to control all the elements leading to responsiveness for mass customization. If many of these supply chain nodes are independent, the harder it is for an independent player herein to deliver a mass customized product. 


\subsection{Key Performance Indicators}

In this part we opted to represent all categories of sustainability elements :

Social Gain, defined as the number of jobs kept in Flanders thanks to mass customization.

Ecology Gain, measured by the difference in carbon footprint between mass customization and standard production.

Economic Gain, via the turnover realized by the Mass Customized product families related to the total turnover of all products combined with the growth rate of the company.

The measurement of social gain and ecology gain is not easy but feasible using realistic alternative scenarios and past experiences as benchmarks.

\section{$5 \quad$ Preliminary Observations}

The measurements on these dimensions have been used to assess the relative position of 17 individual textile companies, who are interested to go along on the road of mass customization. In general, our findings are that there are quite some differences among the MC business models applied and among the mass customization performance of these companies

\subsection{Natives and Hybrid Companies}

More specific, we noticed that companies who started up applying the mass customization business model, "MC natives" have a higher probability of success than established companies who convert to mass customization ("hybrid" group, Fig 1). The latter evolved to a hybrid business model offering both standard goods and mass customized products. Some of these companies are in a transition phase to a business model fully based on customization, while others consider "customization projects" as a type of innovation next to the core business of mass production of standard products and services. Their intention is not to convert fully to MC but to be present in it. MC natives seem to be slightly better equipped for MC with their process technology and point of sales effectiveness. On average, they have a more profound insight in the user needs and some of these companies were established and are being led by users-innovators. In this group, we find mainly products which are performing functionally better when they fit better, like sportswear. However there is also a group of products which are not perceived as being highly user-centric but which are produced with highly performing technology allowing small lot sizes, avoiding large stocks and waste, e.g. in the interior textile business. The hybrid group has not made a final choice for MC yet, and this is observed in many business elements: the culture and employer's mind-set is not equally committed to personalization as it is the case for the MC natives. The business processes, partners and supporting software are not designed for MC, they need to be adapted for it and evolve. 


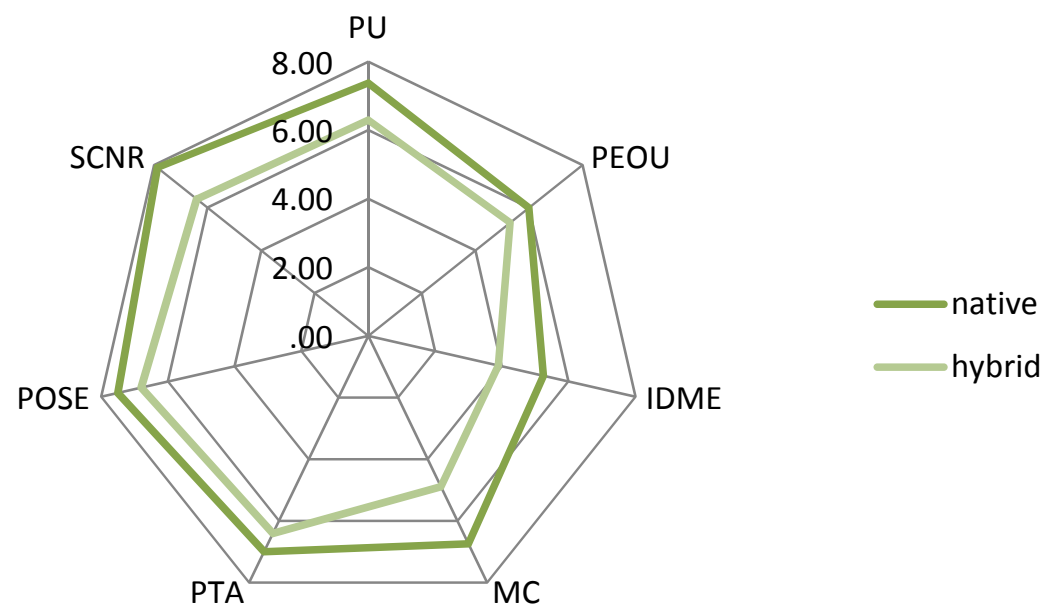

Fig. 1. Mass customization natives versus hybrids in terms of key value dimensions

\subsection{Optimal Degree of Customization Is Key}

We also observed that the degree of customization is a crucial decision to be made by the company. It determines the balance between fulfilling user needs and costs. Once it is fixed, it determines nearly all other performance dimensions of the mass customization business model in the company. It also has a certain effect on the PU of competitor's products as it influences the customer expectations towards customization levels of products and services.

In the confection industry, we still observe a certain resistance to maximize personalization. Mainstream customers are not yet massively prepared to share their detailed biometric data from 3D scanning technology in order to obtain better fitting apparel and save time on shopping. On the other hand, e.g. cyclists and other professional athletes do appreciate the additional functionality and are very much willing to go through a personalization process and accept the higher costs involved. The same elevated PU is sensed by mainstream customers in for instance the bedding industry: a highly effective POS, including for instance an "experience module" in the store and additional expert advice, succeeds in creating a much higher willingness to pay for the customized products.

An uncontrollable and quite unpredictable dimension is the IDME. If it is present, it can have a huge impact on willingness to pay. However, it is a factor which seems very hard to initiate or promote. It is likely to be triggered by hypes or trends but we have no evidence hereof yet. 


\subsection{Application of the Model}

Additionally to natives and hybrids, some interesting clusters can be delineated where companies can use the information in a peer based setting. A more advanced use of the results is where the assessment leads to a gap analysis with subsequent roadmap construction. The assessment of less controllable pull factors, such as PU and IDME and less controllable cost factors such as PTA (based on state of the art technology) give insight in a theoretical opportunity of a customization. When a certain degree of $\mathrm{MC}$ is fixed, it allows to design possible business models with directions for the approach of the customer (PEOU) and the Supply Chain (SCNR, POSE and also PTA) We relate this to the seminal article of Fisher [4], posting that there is a right supply chain for every product. This boils down to the distinction between efficient versus responsive supply chains, serving functional and innovative products respectively. In this way we intend to give additional insight to the textile industry and help them to setup plans to go into the direction of mass customization as a path towards rejuvenation of a suffering industry. We experienced that the representation of the business model building blocks using the business model canvas [7] facilitates company insights in the transition path. We also experienced that introducing sustainability, in the broad sense, and implementing it in decision making, is still a very tough issue.

\section{Conclusions and Further Research}

In short, if we trace back to our research questions posted earlier, we can conclude that:

Mass customization is a viable business model for the Flemish textile industry

The integration of product, process and supply chain design is a way to materialize mass customization.

Future research challenges include the quest for more refined metrics and data collection methods, the inclusion of more companies in to the database and the development of an adequate visualization for better insight and decision making.

Aknowledgments. This research is based on a data which was gathered through the technological innovation supporting programme of the Flemish government "Mass customization for the Textile industry" (2012-2014, IWT095011).

\section{References}

1. Anderson, C.: The Long Tail: Why the future of business is selling less of more. Hyperion (2008)

2. Da Silveira, G., Borenstein, D., Fogliatto, F.: Mass customization: Literature review and research directions. International Journal of Production Economics 72, 1-13 (2001)

3. Davis, S.: From future perfect: Mass customizing. Planning Review 17(2), 16-21 (1989) 
4. Fisher, M.: What is the Right Supply Chain for your Product. Harvard Business Review, 105-116 (1997)

5. Franke, N., Schreier, M., Kaiser, U.: The "I Designed It Myself" Effect in Mass Customization. Management Science 56, 125-140 (2010)

6. Kaplan, A.M., Schoder, D., Haenlein, M.: Factors influencing the Adoption of Mass Customization: The Impact of Base Category Consumption Frequency and Need Satisfaction. Journal of Product Innovation Management 24, 101-116 (2007)

7. Osterwalder, A., Pigneur, Y.: Business Model Generation. Self Published, Amsterdam (2009), http: / / www. businesmodelgeneration. com

8. Piller, F.T., Tseng, M.M.: Handbook of Research in Mass Customization and Personalization. World Scientific Publishing Co., Singapore (2010)

9. Schwartz, B.: The paradox of choice: why more is less. HarperCollins (2005)

10. Zipkin, P.H.: The Limits of Mass Customization. MIT Sloan Management Review 42(3), 81-87 (2001) 